\title{
Evaluating the Cooperation Risk between Rural Tourism and Third-Party Network Platform by Using Confirmatory Factor Analysis
}

\author{
Hui SONG ${ }^{1,2}$ \\ ${ }^{1}$ School of Management Engineering, Suzhou University, \\ Suzhou city, Anhui province, 234000, China \\ ${ }^{2}$ Research Center of Northern Anhui Urban-rural Integration \\ E-mail: songhuisuzhou@163.com
}

\begin{abstract}
$2 l$ century is the era of rapid development of information technology; electronic commerce is an important way to meet consumer demand, to improve the degree of organization. The e-commerce development of rural tourism will meet the need of market economy development, and enhance the competitiveness of tourism enterprises. In this paper, we analyze the cooperation performance between rural tourism and third-party network platform, the result shows that: (1) relationship quality has significant positive effect on direct performance, the coefficient is 0.824; (2) relationship quality has significant positive effect for indirect performance, and the coefficient is 1.012. So that, relationship quality is a key factor that affect the performance of bilateral cooperation. On this basis, we put forward the related suggestions to promote the e-commerce application in rural tourism.
\end{abstract}

Keywords: Rural Tourism, Network Platform, Performance Evaluation, E-commerce

\section{Introduction}

With the coming era of leisure tourism, changing people's way to travel from traditional type to modern type of original, rural tourism has become one of people's choices. Rural tourism is a new tourism form of tourism development in the rapid development of the state, pay more attention to freedom, leisure, and entertainment [1]. 21 century is the rapid development of information technology, electronic commerce is an important way to meet and enhance consumer demand, improve the degree of organization, industry and resources to change the mode of economic development. The electronic commerce development of rural tourism is to meet the need of market economy development, is the need to enhance the competitiveness of tourism enterprises.

Rural tourism is not only the need to the application of e-commerce in response to the government policy of rural informatization construction, more is to improve the rural surplus labor force employment rate, to improve the level of economic development, narrowing the gap between urban and rural areas. Tourism product is a kind of special sense of the product, different from the general product; it is invisible, remote, fragile, integrity and cannot be stored [2]. Electronic commerce has openness, convenience, high efficiency, fast, cheap and unique features, sharing and interactive. Rural tourism electronic commerce application is to meet the need of market economy development. With the popularity of the network, the traditional way to travel is becoming more and more popular, cannot meet the modern people's pursuit of "casual, comforTable, enjoy the" travel experience, cannot meet the needs of the tourism market. Modern life of people pay more and more attention to the 
network search, is the real "remain within doors, know the world thing", the Internet can maximize the collection to the tourist information required. Therefore, the electronic commerce the development of rural tourism has become one of the means of expanding the market, has become an ineviTable trend. Application of rural tourism electronic commerce is the need to enhance the competitiveness of tourism enterprises. First of all, the electronic commerce the development of rural tourism can broaden the channels of information. Through the establishment of rural tourism electronic commerce platform, you can contact the client and supplier, timely grasp the market opportunity, grasp more initiative. Secondly, the electronic commerce the development of rural tourism can broaden sales channels. Rural tourism enterprises can through the electronic commerce to tourism product agent or the information uploaded to the network of tourism products, to attract tourists and agents, and expand sales channels, expand sales. Once again, the electronic commerce the development of rural tourism can reduce transaction cost. According to statistics, rural tourism enterprises to advertise on Internet can increase the sales volume of nearly 10 times, and its cost is only 1/10 of traditional advertising.

The concept of tourism e-commerce began in 1990's, the construction of service for the Tourist Hotel group and airline computer reservation system is regarded as the tourism electronic commerce. In twentieth Century 90 years due to the Internet is gradually applied in the commercial activities, the tourism industry because of its own information intensive and information-based industry, tourism product is intangible and cannot be stored, without distribution characteristics, service become one of the important applications in the field of e-commerce, and the resulting electronic tourism business. Cao, et al., (2006) said tourism electronic commerce is defined as globally through modern information technology especially in the information network and the completion of the various tourism related business activities, trading activities, financial activities and service activities [3]. Hatem (2012) pointed that to the tourism electronic commerce is defined as the sale of the network and electronic products and service transactions through the network order, is a reservation based electronic commerce logistics distribution [4]. At present, the academic circles of tourism e-commerce is not a unitary definition, widely used international is the World Tourism Organization in its publications as E-Business for Tourism, it pointed that the tourism electronic commerce is to improve tourism institutions of internal and external connectivity through advanced information technology (connectivity), AC with the transaction between the improvement of tourism enterprises, tourism enterprises and between upstream suppliers asked, tourism enterprises and tourists, tourism enterprises to improve internal business processes, improve knowledge sharing. Akoumianakis (2014) definition of tourism e-commerce is more scientific [5], he said tourism electronic commerce refers to the realization of the electronic link tourism business activities by means of the advanced network information technology, including released through the network, the exchange of tourism information and business information, by electronic means in the tourism marketing, tourism services through the pre-sale customer service; network inquiry, booking travel products and payment; electronic and information management system including the internal process of tourism enterprise application.

Hojeghan (2011) pointed out that the company was able to decrease in business management and trading process costs through e-commerce, and improve the efficiency of business operations at the same time between the reasonable optimization and partners of the allocation of resources [6]. Michopoulou, et al., (2013) put forward tourism website is rich competitive online service content [7]; improve the core competitiveness of the company's reputation and reputation and outstanding company. Zeng (2014) put forward several problems of tourism online marketing, including the quality of the website, network marketing target market 
positioning, site of the single function [8]. Lee (2006) analyze the current situation of network marketing, including the proposed to strengthen the network infrastructure construction, strengthen the tourism information development, strengthen the interaction with tourists communication from three aspects such as the tourism network marketing development strategy [9]. Buhalis, et al., (2008) from released statistics report respectively limiting technology users of tourism e commerce is the primary means of network users and that the new website is search engine, ranks second in the other links on your site [10]. Busby (2012) think of online reviews has gradually become an important source of customers to collect product information, has a significant effect on the intention of customers booking [11]. McCabe (2012) that the pattern of tourism collaborative e-commerce applications including the construction of collaborative commerce and tourism collaborative electronic commerce, three aspects including tourism collaborative ecommerce functions contain tourism information display, online booking, the personalized service customization [12]. Raventos (2006) leading the way to understand the tourism by team oriented to individual oriented [13], in order to seize the market opportunities, he pointed that the use of e-commerce to develop individual rural tourism market in the strategy involves the strategic significance, personalized tourism products, electronic commerce, make full use of the personalized needs of the investigation and analysis of customer relationship management, etc.. Nusair (2010) through the analysis of the status of Guangxi tourism electronic commerce and the existing problems, and puts forward several countermeasures, mainly including the leading role of the government, the website construction, brand construction and personnel training [14].

The premise to carry out a wide range of cooperation in $\mathrm{B} 2 \mathrm{C}$ e-commerce and the third party logistics, cooperation between the two sides of the same effect. Some large mature B2C e-commerce enterprises due to its operation more standardized, abundant resources, advanced management concepts, so that enterprises in cooperation with the three party logistics has obtained the cooperation performance good, the formation of a sTable long-term cooperation relationship with third party logistics. While some B2C e-commerce enterprises have cooperation performance and the third party logistics is not ideal, the cooperation between the two sides did not reach the effect of one plus one is greater than two, but because of the problems in cooperation and conflict that interrupt cooperation. To sum up, in the premise of logistics must rely on third party logistics function is very important to the enterprise and the reason of the $\mathrm{B} 2 \mathrm{C}$ electronic commerce, in cooperation with the third party logistics performance has great difference, has become a new task put in front of $\mathrm{B} 2 \mathrm{C}$ e-commerce business, but for those who work with third party logistics performance $\mathrm{B} 2 \mathrm{C}$ the business enterprise, this problem is more urgent

\section{Model Design and Hypothesis}

\subsection{The Theoretical basis and Research Model}

The current research on $\mathrm{B} 2 \mathrm{C}$ e-commerce and the third party logistics in the field of domestic and foreign scholars are mostly concentrated in the selection of logistics mode and the third party logistics partner selection, and the study of B2C electronic commerce in cooperation with third party logistics relationship is not much. Therefore the research model the main experience of the traditional manufacturing industry and retail industry and combined with the characteristics of $\mathrm{B} 2 \mathrm{C} \mathrm{e}-$ commerce to establish the research model related.

How to use with the E party logistics to carry out effective cooperation to improve logistics efficiency and effectiveness, improve the network customer 
satisfaction and the formation of the core competitiveness of enterprises, which is the main purpose of $\mathrm{B} 2 \mathrm{C}$ electronic commerce and the third party logistics cooperation. In this paper, we construct the theoretical model of $\mathrm{B} 2 \mathrm{C}$ electronic commerce in cooperation with third party logistics performance influence mechanism. Factors on the cooperation are divided into external environment, the relationship between cognition and the relationship between the three dimensions of quality; cooperative performance from the two dimensions of direct and indirect performance of performance. Study on the relationship between the independent variables in the model are the cognition, the dependent variable is the intermediary variable between cooperative performance, quality, control variables of external environment. The basic idea of this study: the relationship between cognitive model has a direct effect on relationship quality, relationship quality has a direct influence on the enterprise performance, the relationship between cognition through the intermediary role of relationship quality and cooperative performance impact, the external environment has a moderating effect on the relationship between the relationship between cognition and relationship quality.

\subsection{The Definition of Variables}

Relationship quality will ultimately affect the realization of enterprise cooperative target, high quality relationship can promote the cooperation between the two sides reached cooperation performance ideal. Previous studies that have a significant role in the quantity and quality of relationship quality on the cooperation and exchange of information and resources, will directly affect the performance of cooperation. In this paper, the definition of $\mathrm{B} 2 \mathrm{C}$ e-commerce cooperation relationship quality and relationship between the third party logistics for the cooperation between the both sides of positive and long-term cooperation degree, including trust, communication, commitment, adaptation and cooperation in five dimensions. Here were these variables.

The connotation of cooperation is very rich, the degree of intimacy between different enterprises in the cooperation between the different methods, the direct measurement of relationship is not to see. Performance refers to those enterprises engaged in the activities of the performance and efficiency, the realization degree of performance on behalf of the enterprise's strategic target, the efficiency of both the activities of the enterprise also includes the effect of. In this paper, the cooperation performance is defined and the third party logistics cooperation brings to the B2C Electronic Commerce Economic and non economic effects. For the dimension division cooperation performance, this paper includes two dimensions of direct and indirect performance. The direct performance is mainly used to measure the objective indicators, including the cooperation between the two sides of the realization of the goal and satisfaction degree of cooperative target realization; indirect performance mainly include subjective evaluation index, enhance the enterprise competitive advantage and future cooperation.

\subsection{Research Hypothesis}

For the relationship between cognition from three aspects of cultural compatibility, the target relation and complementary resources, influence the quality of the relationship, after the investigation found, has significant positive effect on relationship quality cognition relationship. Many scholars from the single point of view, the relationship between cognition of the relationship between the qualities of it, this paper proposed a hypothesis $\mathrm{H} 1$.

H1: significant correlation between relationship cognition and relationship quality; 
Relationship quality is one of the key variables that affect the relationship quality, relationship to cooperative members asked to continue. The relationship between the quality levels will affect the company performance, thereby affecting the performance of cooperation. High quality means that the cooperation between the two sides have adapted to each other and are willing to continue cooperation, cooperation for cooperation from any of us would mean a big loss, because the establishment of high quality requires a huge investment. So the high relationship quality can make the cooperation between the two sides to establish long-term cooperative relationship, the pursuit of long-term interests and the sustainable competitive advantage, and ultimately to improve the performance of bilateral cooperation. Comprehensive analysis of above on the relationship between relationship quality and cooperative performance, this paper put forward the following hypothesis hypothesis of $\mathrm{H} 2 \mathrm{H} 2.1$ and $\mathrm{H} 2.2$ and its derivatives.

H2: significant correlation between relationship quality and performance;

H2.1: significant correlation between relationship quality and direct performance;

H2.2: significant correlation between relationship quality and indirect performance.

In addition to relationship quality, many scholars found that the relationship between cognition will have an impact on enterprise performance. Study on organization learning and innovation performance of enterprises after the discovery, cooperation on research and development is greatly affected by the enterprise on the relationship between cognitive. A comprehensive analysis of the literatures of domestic and abroad love after the discovery, the relationship between cognition is an important influence factor of enterprise cooperation performance. The extensive research that a conclusion: the relationship between cognition has important influence on cooperation performance. This paper put forward the following hypothesis $\mathrm{H} 3$

H3: relationship quality plays an intermediary role between cognition and cooperation performance

\section{Data Collection and Model Design}

\subsection{Questionnaire Design}

In order to ensure that the results of this study are reliable and ideal, the subjects must meet the following three conditions: (1) the B2C e-commerce enterprises must cooperate with third party logistics. In this paper, the issuance of the questionnaire object must be $\mathrm{B} 2 \mathrm{C}$ e-commerce enterprises; these enterprises products must be physical products, to ensure that the needs of logistics service enterprises. At the same time, because of this study is the influence mechanism, cooperative performance B2C electronic business and the third party logistics. Therefore, the surveyed enterprises to outsource their logistics to the third party logistics, and the two sides have established sTable cooperative relations. This paper sets up the corresponding problems in the background of the formal questionnaire to make sure that the surveyed enterprises can meet the requirement of (2). Respondents to the B2C e-commerce and the third party logistics cooperation must understand, it is best to senior management or logistics department staff. Senior managers of enterprises to understand the situation of a more comprehensive, can make more close to the actual business of the responses to the questionnaire of the subject. Logistics and operations staff is familiar with the logistics and distribution, to better understand the logistics enterprise and third party logistics cooperation than employees in other departments (3). The questionnaire survey of each enterprise has to fill out a 
questionnaire. This study is the cooperation between enterprises, so for every respondents to a questionnaire to understand the relevant circumstances of the company. Set the "company name" questions in the questionnaire to guarantee it.

The characteristics of this research this paper decides to not use large-scale questionnaire. The comprehensive research and the researcher's resources, this paper mainly adopts four kinds of questionnaire: 1) the scene to the respondents providing paper questionnaire. Distribution channels include e-commerce conference held a variety of organizations and agencies, the electricity supplier logistics Forum; 2) through telephone interviews of respondents to fill in. Because of the time and geographical issues, some qualified and willing to fill in the questionnaire respondents were unable to field to fill in the questionnaire, and difficult to use mail questionnaires, therefore need to be interviewed by telephone to ensure timely recovery of the questionnaire through the questionnaire; 3 ) contact. Contacts include teachers, government officials, business executives, individual operators. This paper selected contacts understand with questionnaire asked respondents, and contact was informed in advance of the requirements to ensure the quality of filling out the questionnaire; 4) through the network questionnaire. Because of this questionnaire is $\mathrm{B} 2 \mathrm{C}$ e-commerce enterprise, so the network can communicate directly with the surveyed enterprises staff. So the network distribution is an efficient way of questionnaire. The following questionnaires and recovery situation as shown in Table 1.

Table 1. The Situation of Questionnaires Release and Recycling

\begin{tabular}{|l|l|l|l|}
\hline $\begin{array}{l}\text { The way of } \\
\text { questionnaire }\end{array}$ & Release quantity & $\begin{array}{l}\text { number of } \\
\text { recycling }\end{array}$ & $\begin{array}{l}\text { valid } \\
\text { questionnaires }\end{array}$ \\
\hline The field distribution & 210 & 210 & 210 \\
\hline Telephone interview & 200 & 200 & 183 \\
\hline $\begin{array}{l}\text { Acquaintance } \\
\text { questionnaire }\end{array}$ & 260 & 245 & 195 \\
\hline Network survey & 280 & 196 & 143 \\
\hline Total & 950 & 851 & 731 \\
\hline
\end{tabular}

\subsection{Descriptive Analysis}

The main content of descriptive statistical analysis of sample data is part of the background information questionnaire. Through the descriptive statistics of the questionnaire of background data information analysis can test whether the data from a representative sample, the sample data quality estimate. In this paper, the descriptive statistical analysis of sample data is divided into three parts: 1) basic information of the respondents and descriptive statistical analysis; 2) the descriptive statistical analysis on the basic information of the enterprise under investigation; 3 ) for descriptive statistical analysis on the cooperation of the enterprise under investigation and the third party logistics. For the research of this paper is the performance and its influence factors, the cooperation between enterprises in general, the higher the level of the staff is aware of the information more clearly. From the statistics, questionnaire survey sample of this very ideal as shown in Table 2.

Table 2. Distribution of Respondent's Duties

\begin{tabular}{|l|l|l|l|}
\hline Position & number of samples & The proportion & accumulation ratio \\
\hline general staff & 475 & $64.97 \%$ & $64.97 \%$ \\
\hline First-line manager & 230 & $31.46 \%$ & $96.44 \%$ \\
\hline Top manager & 26 & $3.55 \%$ & $100 \%$ \\
\hline
\end{tabular}


At the same time, we summed up the visitor in the enterprise work experience, as shown in Table 3. The results showed that more than $80 \%$ of the respondents are in the business for more than one year. Because the study of enterprise relationship. In the surveyed enterprises work years longer, respondents to the enterprise will more understand. Taking into account the $\mathrm{B} 2 \mathrm{C}$ electronic commerce is an appearance more than 10 years of industry, so the overall distribution of the sample data can be accepted.

Table 3. Respondents in the Enterprise Work Experience

\begin{tabular}{|l|l|l|l|}
\hline Position & number of samples & The proportion & accumulation ratio \\
\hline Less than 1 year & 122 & $16.67 \%$ & $16.67 \%$ \\
\hline Between 1-3 years & 378 & $51.71 \%$ & $68.38 \%$ \\
\hline More than 3 years & 231 & $31.62 \%$ & $100 \%$ \\
\hline
\end{tabular}

\section{Empirical Analysis}

\subsection{The Reliability and Validity Analysis}

This paper uses the principal component analysis method to carry on the factor analysis. Factor analysis mainly includes the following three steps: 1) KMO samples and Bartlett test of sphericity measurement. For the whole scale, the KMO value is greater than 0.7 is suiTable for factor analysis, Bartlett test of sphericity $\mathrm{x} 2$ significant probability less than 0.05 was suiTable for factor analysis. To determine the participation items or variable factor analysis. Read the back mirror matrix sampling appropriate quantity in MSA and common item extraction common Table after, when MSA value is greater than 0.5 and a total of more than 0.2 items of the homosexual is suiTable for factor analysis of MSA less than 0.5 should be deleted or Co less than 0.2 of the items and confirm the common factor extraction. A comprehensive view of the total variance, scree plot and rotated factor loading value. In the total variance explained only choose initial eigenvaluesmore than 1 factor. Stone diagrams can explain the variance of error correction brings, delete the eigenvalue greater than 1 but the curve is relatively flat factor. The rotation factor load values can be used to determine the internal structure variable is good, the load factor is greater than the general 0.5. The result of KMO statistical test and Bartlett test is shown in Table 4.

Table 4. The Result of KMO Statistical Test and Bartlett Test

\begin{tabular}{|l|c|c|}
\hline \multicolumn{2}{|c|}{ Kaiser-Meyer-Olkin } & 0.783 \\
\hline \multirow{3}{*}{ Bartlett test } & Approximate chi-square & 1162.931 \\
\cline { 2 - 3 } & df & 46 \\
\cline { 2 - 3 } & Sig. & .000 \\
\hline
\end{tabular}

Table 5. The Interpretation of the Total Variance Cooperation Performance

\begin{tabular}{|c|c|c|c|c|c|c|}
\hline \multirow{2}{*}{ Component } & \multicolumn{3}{|c|}{ Initial eigenvalues } & \multicolumn{3}{c|}{ The square shaft and load } \\
\cline { 2 - 7 } & Total & Variance\% & Cumulative\% & Total & Variance\% & Cumulative\% \\
\hline 1 & 7.533 & 77.023 & 77.023 & 6.376 & 65.195 & 65.915 \\
\hline 2 & 1.444 & 14.763 & 91.787 & 2.601 & 26.592 & 91.787 \\
\hline
\end{tabular}

From the Table 4 .we can see that the KMO value is more than 0.7 , significant probability sig. is $0.000<0.005$ and Bartlett test of sphericity of $\chi 2$ values, so the cooperation performance scale can be further factor analysis. All items in the matrix 
inverse image MSA values were greater than 0.5, the common extraction respectively is more than 0.2 , so the cooperation performance scale all items can be a factor analysis. The two factors in Table 5 explained $91.787 \%$ of the total variance, and the initial characteristics of the two factors Selection of root were greater than 1, the factor can meet the requirements. According to the statistical result shows that the cooperative performance scale all seven item of factor load is bigger than 0.8 , so all meet the requirements of more than 0.55 , two factors of extraction is appropriate. Factor 1 contains four items; indirect performance factor 2 contains directly the performance of three items. From Table 6 can be cooperative performance of the overall scale of Cronbach 's coefficient is 0.927 , far more than the minimum requirements is 0.6 .

Table 6. The Reliability of Cooperative Performance

\begin{tabular}{|c|c|c|}
\hline Alpha coefficients & Cronbach's Alpha coefficient & Item number \\
\hline .927 & .927 & 7 \\
\hline
\end{tabular}

Table 7. The Cooperative Performance of the Overall Statistics

\begin{tabular}{|c|c|c|c|c|c|}
\hline Variables & $\begin{array}{l}\text { Secondary } \\
\text { variables }\end{array}$ & $\begin{array}{l}\text { corrected } \\
\text { item-total } \\
\text { correlation }\end{array}$ & $\begin{array}{c}\text { Square } \\
\text { coefficient }\end{array}$ & $\begin{array}{c}\text { Cronbach's } \\
\text { Alpha if } \\
\text { item } \\
\text { deleted }\end{array}$ & $\begin{array}{l}\text { Cronbach } \\
\text { 's Alpha }\end{array}$ \\
\hline \multirow{3}{*}{$\begin{array}{c}\text { Direct } \\
\text { performance }\end{array}$} & Delivery X1 & .716 & .810 & .922 & \multirow{3}{*}{.917} \\
\hline & Inventory X2 & .551 & .551 & .805 & \\
\hline & flexible X3 & .684 & .726 & .915 & \\
\hline \multirow{4}{*}{$\begin{array}{l}\text { Indirect } \\
\text { performance }\end{array}$} & efficiency X4 & .894 & .915 & .921 & \multirow{4}{*}{.958} \\
\hline & profitability X5 & .917 & .956 & .900 & \\
\hline & perceived risk X6 & .819 & .946 & .911 & \\
\hline & potential value $\mathrm{X} 7$ & .804 & .896 & .905 & \\
\hline
\end{tabular}

\subsection{Regression Analysis}

We made multiple linear regression analysis between relationship quality and enterprises performance, and try to find out the mediating effect of the relationship quality. First of all, we analyze the relationship between relationship quality and directly performance by SPSS linear regression, and the model of direct performance (DP), relationship quality (RQ) and indirect performance (IP) can be shown as:

$$
\begin{aligned}
& \mathrm{DP}=\beta_{1}+\beta_{1} R Q+\mu \\
& \mathrm{IP}=\beta_{2}+\beta_{2} R Q+\mu
\end{aligned}
$$

From formula 1, we can get the regression analysis of relationship quality and direct performance, and formula 2 represent the regression analysis of relationship quality and indirect performance. The results are shown in Table 8. From Table 8, we find the adjusted $\mathrm{R}$ square value as 0.607 , shows that relationship quality as the independent variables can explain $60.7 \%$ of the direct performance variation.

Table 8. Model Fitting Inspection Analysis

\begin{tabular}{|c|c|c|c|c|c|c|}
\hline Model & $\mathrm{R}^{2}$ & $\begin{array}{c}\text { Adjusted } \\
\mathrm{R}^{2}\end{array}$ & Std. Coef. & $\mathrm{R}^{2}$ variation & F variation & Sig. \\
\hline 1 & .611 & .607 & .53207 & .611 & 153.768 & .000 \\
\hline 2 & .396 & .393 & 1.0041 & .396 & 65.066 & .000 \\
\hline
\end{tabular}


Table 9. The Correlation Coefficient Analysis

\begin{tabular}{|l|l|l|l|l|l|l|}
\hline \multirow{2}{*}{ Model } & \multicolumn{2}{|l|}{$\begin{array}{l}\text { Non-Standardized } \\
\text { Coef. }\end{array}$} & \multirow{2}{*}{ Std. Coef. } & \multirow{2}{*}{ t } & \multirow{2}{*}{ Sig. } \\
\cline { 3 - 8 } \multicolumn{2}{|l|}{} & B & Std. Err. & Beta & & \\
\hline \multirow{2}{*}{1} & constant term & 1.115 & 0.353 & & 5.602 & 0 \\
\cline { 2 - 8 } & relationship quality & 0.824 & 0.066 & 0.531 & 7.836 & 0 \\
\hline \multirow{2}{*}{2} & constant term & -.103 & 0.676 & & -.156 & .847 \\
\cline { 2 - 6 } & relationship quality & 1.012 & 0.114 & .624 & 8.066 & .000 \\
\hline
\end{tabular}

From Table 9, the results in model one shows that significant probability variable of relationship quality and constant term is less than 0.01 , indicating the constant term and relationship quality is entered into the model. The coefficient $\beta 1$ is $0.824, \mathrm{t}$ is 7.836 and $\mathrm{Sig}$. is 0 , so the coefficient $\beta 1$ is significant and can be used explain the changes of the direct performance. Through the above analysis it can be found that relationship quality has significant positive effect on direct performance. Also, the result in model two shows that relationship quality has significant positive effect for indirect performance. The coefficient $\beta 2$ is 1.012 , $t$ is 8.066 and Sig. is 0 , so the coefficient $\beta 2$ is significant and can be used explain the changes of the in direct performance.

\section{Conclusions and Suggestions}

This paper studies the rural tourism electronic commerce development; we put forward the hypothesis that the relationship between the quality level of the third party logistics cooperation and cooperation performance will have a significant correlation through literature research. After the empirical study found that, in the process of cooperation of electronic commerce and the third party logistics, relationship quality has a significant role in promoting the cooperation between the two sides to improve performance; relationship quality is a key factor to affect the performance of bilateral cooperation. From the point of view of the internal factors of relationship quality included, the higher the degree of trust and cooperation between the two sides, e-commerce will be more and more willing to outsourcing partner operations, and the third party logistics of ecommerce trust are more likely to provide additional service contract, which had a positive effect on cooperative performance. Communication and cooperation between the two sides is more timely, some misunderstandings in the process of cooperation is also more easily in a timely manner to eliminate, the cooperation is also easier to establish a trust relationship, which will have a positive effect on cooperative performance. Commitment to deepen cooperation between the two sides of the base, so that the communication between the two sides to achieve better results, and lay the foundation for the trust, and ultimately achieve the purpose of cooperation performance. In addition, adaptation and cooperation as an important component of relationship quality will have an impact on cooperation performance.

In this paper, the cooperation performance is divided into direct and indirect performance. Through the empirical test, found the relationship quality has a significant effect on the two kinds of performance. Relationship quality has direct effect on the performance, this may be because of the relationship between quality performance and flexible distribution, inventory and other elements of the trust, communication and cooperation, etc.. Relationship quality will have an impact on the cooperation performance, because the indirect performance is a subjective attitude and perception of cooperation, so the evaluation of the performance of the vulnerable to both sides of the communication effect, commitment, trust, cooperation, to adapt to the level of other factors. Based on this, we put forward related Suggestions 


\section{(1) Establishment of Enterprise Self Built Website in Rural Tourism}

Establishment of enterprise self built website, set up their own rural tourism brand, expand brand awareness. Tourists are seeking novelty for tourism demand, so a comprehensive analysis of the surrounding area has been developed and differentiated development, not only to avoid repeated development of homogeneity, and can realize integration, linkage development between regions. If does not have the ability to self built website can also create their own web pages by other rural tourism electronic commerce platform, to achieve the exchange of information and rural tourism, to realize the function of electronic commerce. In addition, self built website to play their own signs, play their own characteristics.

\section{(2) Construct Vertical Integration Platform and Industrial Clusters}

With the rapid development of the information age, the traditional marketing will be eliminated by history; integrated marketing is the hard truth. The key to a country or region is the competitive advantage of industry competitive advantage, and competitive advantage derived from each other industry related industrial clusters. The current tourism market has entered into the stage of rapid development of rural tourism, the competition among enterprises is growing, has been difficult to adapt to it by their own development model, the traditional tourism is also the voice faded in the development of online business to business platform, and even the emergence of traditional tourism mode will disappear argument. Rural tourism electronic commerce and online mode is often fall into the islands of information cannot be shared information, therefore, the formation of strategic alliances, and other enterprises in the same industry or the upstream and downstream enterprises to secure their strategic advantage, the formation of information sharing, resource sharing by the form of rural tourism enterprises welcome. Through the implementation of integrated marketing, collaborative travel agency, tourism enterprises, tourists, to build a cooperative tourism electronic commerce platform based tourism collaborative management system, in order to avoid the information island situation.

\section{(3) Enhance Media Terminal Construction in Rural Tourism}

Living in the information society, information audiences tend to young people, their goal gradually by TV, radio to the network terminal equipment, mobile phone and computer. Research shows that, the Internet query travel information to browse more tourist site. People through the mobile phone, computer and Internet equipment information query of rural tourism, rural tourism services provided by GPS or intelligent facilities, all this led people to travel footsteps. In addition, to provide convenient and efficient service for the city multimedia terminal direct visitors, for visitors to save unnecessary time to better enjoy the journey, as tourists travel on the road to increase the construction of multimedia terminal of rural tourism, it is rural tourism city terminal or terminal.

\section{(4) Innovation in Rural Tourism Electronic Commerce Applications}

Application of rural tourism electronic commerce should conform to the trend of the times, a lot of potential tourists. Not only to speed up the development of rural tourism electronic commerce in the micro blog, micro blog, mobile terminal equipment, application, but also the development of rural tourism, the intelligent robot and intelligent services of rural tourism.. Under the electronic commerce tourism market will be the knowledge, information and personnel quality takes the place of traditional capital and resources as the economic power of economic mode, and tourism training and training mode to adapt to the new requirements. 


\section{ACKNOWLEDGEMENTS}

The work of this paper is supported by National Social Science Youth Fund Project "Research on Rural Tourism Sustainable Development Strategy based on Urban-rural Integration" (No: 13CJY106), the tourism industry in Anhui Province young expert training program (No: AHLYZJ201408); and Colleges and universities in Anhui province provincial natural science research project "Suzhou tourism products and product development" (No:KJ2014A248).

\section{References}

[1] M. Kim and N. Chung, Tourism Management, vol. 32, no. 2, (2011), pp. 256-265.

[2] T. Maswera and J. Edwards, Telematics and Informatics, vol. 26, no. 1, (2009), pp. 12-19.

[3] Q. Cao and M. Schniederjans, Information \& Management, vol. 43, no. 5, (2006), pp. 598-606.

[4] E. Hatem, Tourism Management, vol. 33, no. 5, (2012), pp. 1256-1269.

[5] D. Akoumianakis, Computers in Human Behavior, vol. 30, (2014), pp. 773-786.

[6] S. Hojeghan and A. N. Esfangareh, Procedia - Social and Behavioral Sciences, vol. 19, (2011), pp. 308316.

[7] E. Michopoulou and D. Buhalis, Information \& Management, vol. 50, no. 5, (2013), pp. 229-239.

[8] B. Zeng and R. Gerritsen, Tourism Management Perspectives, vol. 10, (2014), pp. 27-36.

[9] G. Lee and L. Cai, Tourism Management, vol. 27, no. 5, (2006), pp. 815-828.

[10] D. Buhalis and R. Law, Tourism Management, vol. 29, no. 4, (2008), pp. 609-623.

[11] G. Busby and R. Huang, Tourism Management, vol. 33, no. 1, (2012), pp. 108-115

[12] S. McCabe, Tourism Management Perspectives, vol. 4, no. 2, (2012), pp. 36-44.

[13] P. Raventos, Journal of Business Research, vol. 59, no. 3, (2006), pp. 375-386.

[14] K. Nusair, Tourism Management, vol. 31, no. 3, (2010), pp. 314-324. 
International Journal of Security and Its Applications Vol. 9, No. 5 (2015) 